\title{
Pais ouvintes, filhos surdos: barreiras na comunicação
}

\section{Listeners deaf, children parents: barriers in communication}

Helena dos Santos Silva Gianoto ${ }^{1}$ Adriano de Oliveira Gianotto ${ }^{2}$ Heitor Romero Marques ${ }^{3}$

${ }^{1}$ Licenciada em Letras pela Universidade Católica Dom Bosco (UCDB) e Especialista em Educação Especial pela mesma universidade. E-mail: msgianoto@uol.com.br

${ }^{2}$ Licenciado em Pedagogia (UNIASSELVI). Especialista em Libras e Educação Especial com ênfase em Deficiência Auditiva (UNIASSELVI). Mestrando em Desenvolvimento Local pela UCDB. E-mail: adriatto@outlook.com

${ }^{3}$ Licenciado em Ciências e Pedagogia pelas Faculdades Unidas

Católicas de Mato Grosso (FUCMT). Especialista em Filosofia e História da Educação (FUCMT). Mestre em Educação - formação de professores (UCDB). Doutor em Desenvolvimento Local y planteamiento territorial pela Universidad Complutense de Madrid. E-mail: heiroma@ucdb.br 


\section{RESUMO ABSTRACT}

0 presente artigo objetiva uma reflexão de que a surdez não é um obstáculo para a comunicação de fato, a linguagem de sinais é o caminho para a integração social dos deficientes auditivos, mas é preciso compreender que todo o processo de ensino e aprendizado dos conteúdos nas escolas regulares tende a ser retransmitido, traduzido, para outra língua. Respeitar as especificidades de cada forma de comunicação estima ser o caminho para que não haja divergências quanto àquilo que está sendo transmitido aos alunos surdos. As barreiras na comunicação entre membros da família e sociedade é um fato organizador deste artigo, numa assertiva de enfrentar a problemática da surdez. Esta pesquisa de natureza realizada por meio de estudos bibliográficos e de campo com famílias de surdos tem o intuito da inclusão da pessoa surda no ensino regular e seus reflexos no processo de aprendizagem.

PALAVRAS-CHAVE

surdez barreira comunicacional família de surdo
This article aims to reflect that deafness is not an obstacle to the fact that communication, sign language is the path to social integration of the deaf, but you must understand the whole process of teaching and learning of the contents in regular schools tends to be retransmitted, translated into another language. Respecting the specificities of each form of communication estimated to be the way so that there is disagreement as to what is being transmitted to the deaf students. Barriers in communication between family members and society is an organizing fact of this article, a statement to address the problem of deafness. This kind of research conducted through bibliographic and field studies with deaffamilies have the intention of including deaf person in regular education and its effects on the learning process.

\section{KEY WORDS}

deaf communicational barrier família of deafness 


\section{INTRODUÇÃo}

0 presente trabalho emerge de pesquisa que tem como objetivo caracterizar a situação de alunos surdos, cujos membros familiares são todos ouvintes. Na contemporaneidade, os estudos e pesquisas da Educação Especial no ensino regular contribuem para o desenvolvimento humano em diversas áreas da educação, em cujo contexto a escola grita por socorro. Dessa maneira, a investigação se tornou uma grande aliada do professor em sala de aula cujo eixo norteador é a metodologia participativa, buscando intensificar as inter-relações entre a escola, a família e o aluno de forma produtiva.

Propõe esse tema auxiliar os profissionais, familiares e até mesmo os próprios surdos que lidam com pessoas que têm filhos surdos que não aceitam a língua de sinais para relacionarem-se melhor entre si. Nas informações dos familiares, há formas diferentes para cada caso, por exemplo, existe mãe que rejeita o uso da Língua Brasileira de Sinais (LIBRAS), para o filho. E, em outra família a LIBRAS é adotada pelo filho surdo como primeira língua, e assim os pais vão se adequando nos quesitos, aceitação e comunicação com o surdo.

Essa situação se mostra muito comum e é observada em muitas famílias, perante a deficiência auditiva de um filho. Muitos pais têm insegurança em não saberem dar condição favorável e, nesse contexto, o presente estudo visa contribuir com um novo olhar para as mudanças que se fazem necessárias para a adaptação de ambos.

Este artigo discorre inicialmente sobre a família, segue com discussão do aprendizado da língua de sinais na escola com o intuito de problematizar a questão do aprendizado tardio da língua de sinais e fora do seio familiar, finalizando com explanação dos dados coletados com familiares e surdos. Ressalta-se que o aprendizado da LIBRAS pela família é de extrema importância para o perfeito desenvolvimento da criança surda. 


\section{APRENDIZADO DA LÍNGUA DE SINAIS NA FASE ESCOLAR, O ATENDIMENTO EDUCACIONAL ESPECIALIZADO PARA O SURDO}

A trajetória desta pesquisa se inicia com a contribuição de Nikitiuk (1999, p. 31) quando assevera que uma nova concepção de ensino está sendo fundamentada principalmente nas teorias de Piaget e Vygotsky, cuja concepção construtivista fornece subsídios para a superação das aulas expositivas como metodologia exclusiva, apontando caminhos para um ensino que estimule o desenvolvimento cognitivo dos alunos em direção a níveis qualitativos superiores.

Antigas concepções educacionais podem não ser as condições adequadas de espaços de aprendizagem, em que todos envolvidos podem aprender a se comunicar, gerando uma culminância entre escola e família, resultando na melhor adaptação do surdo. Desconstruindo os modelos rígidos e excludentes, a recente organização escolar da inclusão prioriza uma nova concepção de aprendizagem que fundamenta a prática pedagógica. 0 professor, então, passa a agir como mediador da aprendizagem, dando sentido às ações e mobilizando as atividades executadas.

Para as ciências humanas, o sistema linguístico, por meio da utilização de signos, é o meio de comunicação que todos os seres humanos possuem, e por sua vez é desenvolvido culturalmente. A aquisição da linguagem, capacidade específica de cada indivíduo, tem um lugar privilegiado no desenvolvimento cognitivo, visto que se inicia nos primeiros anos de vida e modela todo o comportamento humano. É de grande importância para o desenvolvimento futuro que quanto mais cedo a criança estiver em contato com a sua língua natural, de acordo com o desenvolvimento de suas capacidades, mais cedo ela se reconhece como indivíduo inserido na comunidade em que vive. Antes mesmo de a criança desenvolver uma língua própria, o processo dessa aquisição começa após o 
seu nascimento e desenvolve-se ao longo de toda sua formação como indivíduo pensante. Assim, segundo Fernandes e Correia (2006, p.18)

Propiciar à pessoa surda a exposição a uma língua o mais cedo possível, obedecendo às fases naturais de sua aquisição é fundamental ao seu desenvolvimento; privá-la desse direito, sob qualquer alegação, é desrespeitá-la em sua integridade.

Os surdos fazem aquisição de língua na maioria das vezes na escola, decorrente do desconhecimento da família. Para o ensino de libras no ensino regular, o governo oferece o Atendimento Educacional Especializado (AEE), qual seja, um serviço de apoio a esses alunos. Apesar da orientação para que esse atendimento aconteça em salas de recursos multifuncionais, atendendo a todos os alunos com necessidades educacionais especiais incluídos, a organização dessa proposta nas escolas comuns exigiu a sistematização de diretrizes para cada área específica.

Assim, o Ministério da Educação (MEC) se empenhou em produzir materiais para distribuir nas escolas e, simultaneamente, passou a oferecer cursos de capacitação. Dentre os materiais produzidos há um livro específico para a pessoa com surdez, que orienta que o AEE aconteça em três momentos específicos e distintos, organizados em um período adicional às horas diárias de estudo. Dessa forma, a proposta do AEE para alunos surdos se apresenta em momentos e são organizados das seguintes maneiras:

O Momento de atendimento educacional especializado em Libras, em que os conhecimentos produzidos na escola são explicados em Libras por um professor, sendo o mesmo preferencialmente surdo. Orienta-se que este trabalho seja realizado diariamente; 0 Momento de atendimento educacional especializado para o ensino de Libras, em que os alunos com surdez terão aula de Libras, favorecendo 
o conhecimento e a aquisição de termos científicos. Este trabalho deve ser realizado preferencialmente por um professor e/ou instrutor de Libras e deve ser planejado de acordo com o diagnóstico do conhecimento que o aluno tem da língua; 0 Momento do atendimento educacional especializado para o ensino da Língua Portuguesa, em que são trabalhadas as especificidades da Língua Portuguesa. Orienta-se para que este trabalho seja realizado todos os dias, por um professor de Língua Portuguesa, planejado a partir do diagnóstico do conhecimento que o aluno tem da língua (BRASIL, 2013, p. 288).

Percebe-se que, para esse atendimento acontecer com qualidade, faz-se necessária a presença, na escola, de pelo menos dois profissionais distintos, além do professor responsável pela sala de recursos multifuncionais: o instrutor de Libras e o professor de Língua Portuguesa. Orienta-se a troca de conhecimentos em Libras e o ensino da LIBRAS a partir do repertório linguístico do aluno.

A palavra preferencialmente abre a possibilidade de um intérprete e tradutor de Libras/Língua Portuguesa realizar esse atendimento. É preciso destacar que o instrutor de LIBRAS deve ser formado para a realização desse trabalho, o que tem acontecido lentamente no país, reforçando a possibilidade de atuação do intérprete.

No atendimento direcionado ao ensino de Língua Portuguesa, a orientação é que o professor planeje as atividades a partir do conhecimento do aluno da língua. Aqui se está diante de outro problema de formação, pois, para se diagnosticar de forma adequada o conhecimento de Língua Portuguesa de um aluno surdo, é preciso entender que essa língua não é a sua primeira língua, mas sim a segunda e deve ser exigida apenas na modalidade escrita.

Dessa forma, o ensino de Língua Portuguesa para surdos é um dos grandes dilemas da inclusão no ensino regular, pois esse aluno precisa internalizar uma língua alfabética (Língua Portuguesa) a partir de uma Língua não alfabética (Língua de 
Sinais), já que o aprendizado de uma segunda língua passa pela referência da primeira língua. Para que isso ocorra, faz-se necessária uma metodologia específica, de ensino de segunda língua e, geralmente, os professores de Língua Portuguesa não são formados para tanto. Entretanto a Língua Portuguesa vem sendo ministrada inadequadamente para os alunos surdos, num contexto de metodologias que elegem o Português como língua "materna", ou seja, com as mesmas metodologias de ensino de Língua Portuguesa para ouvintes.

Conforme Quiles (2010), os surdos têm condições de "mergulhar" no mundo da leitura e da escrita, entretanto esse caminho deve ocorrer a partir de processos visuais de significação. Para que esse "percurso" aconteça, a Língua de Sinais precisa ser privilegiada. Nesse sentido, Fernandes e Correia (2006, p. 06) destaca que:

Aprender o Português decorrerá do significado que essa língua assume nas práticas sociais (com destaque às escolares) para as crianças e jovens surdos. E esse valor só poderá ser conhecido por meio da língua de sinais. O letramento na língua portuguesa, portanto, é dependente da constituição de seu sentido na língua de sinais.

Considerando todas as proposições acima indicadas, é preciso destacar que o AEE para surdos não pode "abrir mão" de nenhum dos três momentos propostos, pois o aluno precisa ter proficiência em Libras para entender a Língua Portuguesa. Porém todos os profissionais que irão atuar com esse aluno precisam estar conscientes de suas singularidades linguísticas e preparados para somar em seu processo de escolarização.

Nesse sentido, o AEE para surdos deve ser um trabalho de parceria entre o professor da sala de recursos multifuncionais, 0 intérprete e tradutor de Libras/Língua Portuguesa, os professores da classe comum, o instrutor de Libras e os professores de Língua Portuguesa (tanto o que atua na classe regular, quanto o respon- 
sável pelo momento de ensino de Língua Portuguesa no AEE). Os alunos, dessa forma, são observados por todos os profissionais que trabalham com ele, devendo ser focalizados os seguintes aspectos: sociabilidade, cognição, linguagem, afetividade, motricidade, aptidões, interesses, habilidades e talentos (DAMAZIO, 2007).

Por todas as questões apontadas, é de fundamental importância a revisão constante das escolas sobre a qualidade da educação que tem sido oferecida e, na perspectiva da educação inclusiva, pensar sobre os tipos de AEE ofertados, o público alvo a quem eles se destinam, a formação dos profissionais que atuam nas salas de recursos multifuncionais, bem como o estabelecimento de um trabalho em equipe de todos os setores da escola.

\section{FAMÍLIA: BARREIRAS NA COMUNICAÇÃO}

É na família que se inicia a sociedade, nela os indivíduos organizam conceitos e buscam a maturidade por meio de trocas entre seus membros. Por esse motivo, as maneiras de educar são incessantes. Trata-se de um processo que vai do nascer ao morrer, sendo a família considerada, via de regra, a principal responsável pela formação do caráter de uma pessoa.

A Declaração de Salamanca (ONU, 1994), sobre princípios, política e prática em Educação Especial, reafirma o direito de todos à educação, conforme a Declaração Universal dos Direitos Humanos (1948), e reconhece as necessidades educacionais especiais dentro do sistema regular de ensino.

A educação inclusiva caracteriza-se como um novo princípio educacional, cujo conceito fundamental defende a heterogeneidade na classe escolar, como situação provocadora de interações entre crianças com situações pessoais as mais diversas. Além desta interação, muito importante para o fomento das aprendizagens recíprocas, propõe-se e busca-se uma pedagogia que se dilate frente às diferenças do alunado (BEYER, 2006, p. 73 apud DRAGO, 211, p.439). 
A educação inclusiva se aplica na inserção dos alunos com necessidades educacionais especiais (NEE) nas classes regulares de forma incondicional, completa e sistemática, representando considerável avanço na história da educação, principalmente em relação ao movimento de inclusão. Ainda há predomínio de um modelo empirista de transmissão de conteúdo, especialmente a partir dos anos iniciais do ensino fundamental. Há pouca valorização das diferentes formas de expressividade da criança (música, dança, artes visuais, poética) e ênfase na reprodução de modelos transmitidos apenas sobre os conteúdos que são valorizados e perpetuados no currículo escolar.

A família de uma forma única deve estabelecer o seu papel na formação dos indivíduos. Os primeiros passos para o desenvolvimento natural e social do ser humano são dados dentro da família, pois ela constitui o primeiro grupo no qual a criança é inserida e tem suas primeiras experiências e relacionamentos interpessoais.

Em uma família com filho surdo, acrescenta-se a função da aprendizagem de outra língua, a Língua Brasileira de Sinais. É por meio da comunicação que o ser humano se integra, participa, convive e se socializa, a partir da família. Nesse processo, a família aparece como grande responsável, pois é nela que se inicia a primeira formação do ser humano. Para isso acontecer, é necessário o estabelecimento de um canal de língua comum.

Ao se refletir sobre a família, observa-se que esta, ao interagir com os filhos, ajuda a formar a personalidade, determinando suas características sociais. As atitudes e comportamentos dos pais e demais membros familiares, expressos por suas interações, têm um impacto decisivo no desenvolvimento psicossocial de um filho.

Os cuidados oferecidos pela família constituem estratégias que favorecem o desenvolvimento humano à medida que proporcionam amor, afeto, proteção e segurança dentro de um espaço de inclusão e acolhimento aos filhos. Dessa forma, qualquer um 
desses processos, ao sofrerem alterações, acarretam mudanças na comunicação oral.

Manzini e Deliberato (2006) explicam que, em alguns tipos específicos de deficiências, existe a dificuldade da expressão e da fala, como na deficiência mental ou na paralisia cerebral; neste último, o indivíduo pode ter boa habilidade cognitiva, porém a dificuldade na fala ocorre porque não consegue articular ou produzir fala. A falta de comunicação constitui o principal empecilho no relacionamento entre os filhos surdos e seus genitores ouvintes.

Essa dificuldade de comunicação resulta na falta de identificação da língua, podendo resultar em problemas emocionais, falta de um contato mais próximo e dificuldades para o estabelecimento dos vínculos de afeto. Sendo assim, o aprendizado da LIBRAS pela família é de extrema importância para o perfeito desenvolvimento da criança surda.

O diagnóstico da surdez, em alguns momentos, não deve ficar apenas na esfera dos pais, os profissionais da área de saúde são agentes norteadores, a fim de repensar qual é a relevância de um diagnóstico precoce e ou tardio e seus efeitos na relação familiar. Muitas vezes, essas nomeações de surdez, até acompanhada de outras patologias como: psicótico, deficiente mental, hiperativo etc., impedem que outros atributos e particularidades, antes imaginadas pelos pais, sejam faladas e incluídas na vida da criança, pelo peso que o diagnóstico clínico causou.

É perceptivo que, quando se lida com crianças, os profissionais envolvidos são surpreendidos com as possibilidades de cada uma delas, sendo assim, não se pode ter a ingenuidade de colocar todas no mesmo plano por apresentarem um mesmo quadro clínico.

É fundamental ressaltar que a estruturação psíquica de qualquer pessoa vai além do aparato orgânico e de nomeações diagnósticas. É preciso entender e apostar na criança levando em consideração seus pedidos, anseios, seu lugar no discurso dos 
pais, pois, dessa forma, ela poderá se constituir enquanto um ser pensante, desejante, singular e, ao mesmo tempo, pertencente a um laço social.

Os pais são os principais associados no tocante às necessidades educativas especiais de seus filhos, e a eles deveria competir, na medida do possível, a escolha do tipo de educação que desejam seja dada a seus filhos (Declaração de Salamanca, Art. 60, p. 43). A mesma Declaração de Salamanca enfatiza em seu Art. 61, p.43, in verbis:

Deverão ser estreitadas as relações de cooperação e apoio entre administradores das escolas, professores e pais, fazendo que estes últimos participem na tomada de decisões, em atividades educativas no lar e na escola e na supervisão e no apoio da aprendizagem de seus filhos.

Quando uma criança surda nasce, seus pais ou responsáveis sentem-se impossibilitados de agir normalmente com ela. Apresentam-se fragilizados nos primeiros tempos, encontram inúmeras dificuldades à sua frente e, quase sempre, alteram seus planos de vida em função dessa nova situação. A presença do filho surdo terá um impacto na rotina familiar.

As tensões e desafios de criar uma criança surda estão associados, segundo Calderon \& Greenberg (1999), a aprender novos métodos de comunicação, estar mais envolvido nas tomadas de decisões sobre educação, aumentar contato com diversos profissionais das mais diversas áreas e comprar e utilizar suportes técnicos, assim como a experiência do dia-a-dia de ter uma criança que é "diferente", pois se comunica de maneira diferente. (MAIA; ARÁOZ, 2016).

A comunicação de surdos em famílias de ouvintes, muitas vezes também pode ser complicada, porque os ouvintes, diferentemente dos surdos, possuem outros modelos e necessidades de comportamento visual. Durante os cinco primeiros meses de vida, a criança tem mais o contato visual. Depois disso, ocorrem mu- 
danças por interesse em objetos e a família (caso mais frequente a mãe) compartilha dessa atenção com comentários, aponta, faz gestos, mímicas, com o filho surdo, por isso a comunicação fica prejudicada com o filho surdo, por não acompanhar o som ao contato visual.

A língua, distinta da fala, é um objeto que se pode compreender separadamente. Enquanto que a linguagem é heterogênea. A língua é um sistema de signos que exprimem ideias e é comparável, por isso, à escrita, ao alfabeto dos surdos-mudos. A expressão surdo-mudo é incorreta: o surdo não fala porque não recebe sons que sirvam de parâmetro auditivo para repetir. 0 termo correto é surdo. Os ritos simbólicos e sinais militares etc. podem ser também um sistema de sinais acústicos orais, que funcionam na intercomunicação de uma coletividade (RIDENTI, 2010).

A comunicação se torna bastante sensível, e, para que a criança surda solidifique os vínculos sociais e pessoais com a família, faz-se necessário ser compreendida e compreender o que ocorre ao seu redor.

As expectativas dos pais, a aceitação e adaptação à surdez e o bom funcionamento familiar causam grandes impactos na vida das crianças surdas. As identificações, se foram precoces, a aceitação da surdez ajudam a família a se ajustar, e os benefícios dessas atitudes solidificam um desenvolvimento linguístico de habilidades emocionais mais estruturado para a vida acadêmica e social da criança surda.

Ressaltando a questão na situação da surdez, a ideia do corpo incapaz propagou a incapacidade do surdo para utilizar a linguagem, reforçou um privilégio infundado do sistema auditivo / oral de comunicação, imputando ao surdo uma suposta deficiência linguística que determinou uma visão das pessoas surdas como um grupo físico diferente, como se fossem uma raça diferente, culminando com a criação de um racismo da língua. Quando a conversa é gerada pelas mãos e recebidas pelos olhos, a maioria 
das pessoas supõe que não se está lidando com a linguagem como tal. Cada família adquire seu aprendizado em lidar com a deficiência, e as experiências são parte integral para o desenvolvimento (RIBEIRO, 2012).

\section{FAMÍLIA: REFLEXÃO E EXPERIÊNCIA}

Na expectativa dos pais em relação à criança idealizada, estes reagem ao nascimento do filho deficiente como uma situação de frustração, pois a reação inicial depende da situação psicológica que antecede ao nascimento da criança, de como era a interação do casal, e o clima emocional antes do evento que resultará em triste frustração.

Para produção deste texto, foram utilizados questionários e visitas a três famílias, cujas experiências são transcritas a seguir e, em alguns casos, o relato faz parte do texto conforme foi dito pelo próprio entrevistado.

A vivência real de famílias com filhos surdos proporciona a investigação e a busca de um novo olhar para entender como essa comunicação funciona. Após a revisão bibliográfica de obras cujos temas fornecem suporte para elaboração crítica e reflexiva sobre a questão da comunicação de ouvintes com surdos, destaca-se a importância do surdo bilíngue, no ambiente globalizado.

Inicialmente espera-se um ajustamento que se faz necessário após o diagnóstico da deficiência, que o é do sentimento de perda, especialmente em casos de surdez, já que, por não ser visível ao nascimento, os pais só começam a suspeitar que algo está errado um pouco mais tarde. Nesse sentido Luterman (1979 apud SILVA; ZANOLI; PEREIRA, 2008) descrevem que:

[...] o segundo estágio é o de reconhecimento, em que os pais reconhecem a calamidade da situação e começam a admitir a situação emocional. No entanto, pode aparecer alguma reação, como os pais se sentirem oprimidos e inadequados 
para a tarefa de criar um filho surdo, e/ou o sentimento de confusão total, por não compreenderem muitos termos e procedimentos desconhecidos em um curto período de tempo, o que pode levá-los a uma reação de pânico. Outros sentimentos podem emergir nesse estágio, como raiva, depressão, culpa e a superproteção.

Nos três casos estudados, tanto pai quanto mãe são ouvintes e possuem apenas parentes distantes com deficiência auditiva, mas nunca tiveram contato com a Língua Brasileira de Sinais antes do real diagnóstico. Na busca por ajuda, tiveram o acesso a LIBRAS através de instituições públicas e filantrópicas que servem a comunidade no acompanhamento para famílias que as procuram. Os pais entrevistados foram todos conclusos em ressaltar que, desde quando desconfiaram que a criança não ouvia, a maioria deles passou a testar a audição dos filhos para verificar se suas suspeitas eram verdadeiras.

Destacam-se a seguir os relatos das famílias de Pedro, João e Antônia, cujos nomes são fictícios.

Pedro foi diagnosticado quando tinha três anos, na casa de um tio em férias; os familiares procuraram ajuda na cidade de São Paulo, e foram feitos os exames constatando que ele era surdo. Tanto a família estimulou Pedro, que, precocemente depois do diagnóstico da surdez, se empenhou em buscar ajuda e aprender a LIBRAS, compreender como outra forma de se comunicar os ajudaria para toda vida. 0 aprendizado se deu em contato com a escola regular, assim com os encaminhamentos educacionais para a escola especializada. Após a adaptação, com o passar de cinco anos, a família já estava adaptada e preparada para prosseguir e apoiar a necessidade do uso de uma nova forma de comunicação. Pedro está com 32 anos, é casado com uma surda, licenciado em pedagogia e mestrando em Desenvolvimento Local. É professor e intérprete da LIBRAS na rede pública de educação e pretende continuar os estudos ao nível de Doutorado. 
A história de João remete a uma diferente vertente da reflexão e experiência familiar. Aos 28 anos João sofreu um Acidente Vascular Cerebral (AVC), ficando com o lado direito do corpo todo paralisado e, por isso, tem muita dificuldade em se movimentar e fazer os sinais, pois usa só o lado esquerdo. Antes de isso acontecer, ele teve muitas oportunidades de fazer muita coisa boa para ser uma pessoa financeiramente bem, segundo a família, mas não aproveitou, ficou durante 4 quatro anos desaparecido. Quando a família o encontrou, ele estava quase morto, devido ao AVC e a uma surra que havia levado. Essa informação foi dada à família pelo hospital onde o encontraram. João destaca a irmã que sempre foi sua responsável:

Meus pais não criaram ele, mas o pouco que sei, nossa mãe teve rubéola na gestação, eles eram muito reservados, descobriram quando o João já era grande. No começo procuramos ajuda, porém, todos da família que se propunham aprender LIBRAS não tinham sucesso. Logo ficou somente João que hoje sabe pouco, mas o único a tentar se desenvolver.

Os estudos a respeito dos déficits emocionais dos surdos revelam que a falta de linguagem acarreta falha do desenvolvimento das estruturas emocionais. A privação da audição gerava isolamento, introspecção, imaturidade, instabilidade, apatia, irritabilidade, impulsividade, cólera, agressividade, dependência, insegurança, ansiedade, egocentrismo, reações psicóticas, desmotivação, distração, rigidez de juízos e opiniões, pobreza de estruturas associativas e conceituais, prejuízo no desenvolvimento da personalidade e no processo de identificação. As características emocionais descritas acima foram consideradas patológicas e influenciaram o não desenvolvimento positivo do caso (LANE, 1992).

Expondo outra experiência, analisa-se a seguir o caso de Antônia que nasceu de uma gravidez de rubéola citomegalovírus e toxoplasmose. Todos esses vírus causam estragos em quase todo 
o corpo: coração, audição e mente. Nesse caso, segundo a família, uma equipe multidisciplinar de médicos está analisando se ela futuramente não perderá a visão, tendo outras limitações físicas além da surdez, Antônia está inserida junto com seus familiares no curso de LIBRAS, através do Centro Estadual de Atendimento ao Deficiente da Audiocomunicação (CEADA), mas o acúmulo de diagnóstico mostra que Antônia necessita de mais cuidados. Esta se ampliou para a incapacidade de compreender, de falar, de realizar trabalhos escolares, de desempenhar atividades intelectuais e de socializar-se. Desse modo, o termo deficiência abrange um efeito total sobre o indivíduo em todos os aspectos de sua vida.

Para estudar os casos acima, foi necessário identificar diversos aspectos direcionados ao desenvolvimento e aprendizagem, começando na escola e posteriormente na família. Sendo assim, o processo para uma aprendizagem eficaz dependeu de inúmeros fatores, dentre os quais, os mais prementes são: o talento do professor, o tipo intelectual do aluno, as oportunidades oferecidas pelo ambiente imediato da escola bem como as perspectivas de vida do aluno. Essas premissas poderão explicar a natureza do problema, sendo que, no contato com as famílias, percebeu-se que todas se mostraram atentas e buscam apoiar e incentivar seus filhos e compreendem a importância em participar da rotina escolar destes.

\section{CONSIDERAÇÕES FINAIS}

Considerado um grande avanço na educação de surdos, o AEE está respaldado legalmente. Por outro lado, a maneira como esse serviço é oferecido precisa ser analisada para que não seja mais uma ferramenta a favor do não aprendizado e, consequentemente, da exclusão nos âmbitos educacionais. Os documentos preveem serviços que requerem cautela, pois envolvem outros aportes que não estão sendo levados em consideração, como por 
exemplo a organização do trabalho pedagógico na escola como um todo. Sendo assim, depara-se com uma série de questionamentos que impulsionam a estudos e pesquisas que problematizem sua execução.

No caso específico do AEE para os alunos com surdez, faz-se necessário garantir a presença de instrutores surdos, intérpretes educacionais proficientes em LIBRAS e professores de Língua Portuguesa preparados para o ensino de Língua Portuguesa como segunda língua, além disso, os professores responsáveis pelas salas de recursos multifuncionais e os professores regentes devem estar atentos às singularidades linguísticas do aluno surdo e precisam estabelecer um trabalho de colaboração, para que tanto na sala de aula comum quanto no momento do AEE esse aluno possa ser contemplado em suas necessidades.

Para tanto, a LIBRAS além de ser priorizada na família também deve ser priorizada em todos os contextos escolares e as atividades, que muitas vezes envolvem adaptações curriculares, devem ser elaboradas de forma significativa, a partir do repertório do aluno em LIBRAS e em Língua Portuguesa. Assim, o escopo da educação para surdos, na perspectiva inclusiva, é dizer que o aluno surdo tenha um desenvolvimento cognitivo-linguístico equivalente ao verificado no aluno ouvinte. Isso só será possível se a LIBRAS, além de ser entendida como primeira língua do aluno surdo, for valorizada na escola como um todo.

Atualmente, a comunidade surda, por meio do resgate de sua cidadania, apresenta um reencontro com sua cultura e sua história, reescrevendo-a sobre seu olhar, reivindicando o direito legítimo de falar sobre si mesmo, visando romper com a descrição, classificação e o rótulo de comportamentos imputados a si e que a transformaram em incapacitada, arrancando-lhe o direito de viver em liberdade e de ter escolhas e possibilidades de futuro.

O olhar para as diferenças parte do princípio de que, ao nascer, a pessoa é precedida pela linguagem e imersa em um 
mundo simbólico/cultural que fala dela, ou seja, diz quem ela é, os valores da comunidade a que pertence, situando-a. A língua que aprende, a maneira que se alimenta, o jeito que senta, que anda, que brinca está codificado, ficando submetido a regras que dirigem seus movimentos. Essas regras são necessárias para ser possível o convívio em comunidade e vão se modificando com a criação de novas formas de viver, uma vez que a pessoa é dotada de inúmeras potencialidades que necessitam ser constantemente atualizadas para viver e sobreviver mediante o complexo processo evolutivo.

A linguagem, então, perpassa esse complexo evolutivo e vem em sua origem como consequência da necessidade de transformar a natureza, pela cooperação entre as pessoas, por meio de atividades produtivas que garantam a sobrevivência do grupo social. Com ela foi possível à pessoa agir, ampliando as dimensões de espaço e tempo. Produto de uma coletividade, a linguagem, reproduz por meio dos significados, das palavras e/ou sinais, valores associados a práticas sociais que se solidificaram. Dito de outro modo, a linguagem reproduz uma visão de mundo, produto das relações que se desenvolveram a partir do trabalho produtivo, para a sobrevivência do grupo social.

Os surdos têm na língua de sinais sua maior expressão. É por meio dela que se comunicam livremente, sem limites, elaborando hipóteses sobre o mundo e as próprias ideias e pensamentos sobre os diversos conceitos. A língua de sinais não é apenas um meio de comunicação, é um conjunto de conhecimentos culturais, um símbolo de identidade social, da história e dos valores e costumes dos surdos.

Todo ser humano tem necessidade de contato com sua comunidade, com seus iguais para poder estabelecer as diferenças. Dentro de sua comunidade, o surdo tem a possibilidade de identificar-se com seus iguais pela interação entre seus membros. Os surdos, que desde cedo se integram na comunidade surda, consideram-se pessoas essencialmente visuais, com uma lingua- 
gem visual, uma organização social, uma história e com valores culturais que lhe são próprios, assegurando uma teoria sobre o mundo e a formação de uma identidade pessoal.

Sendo assim, conclui-se que as famílias, em sua maioria, ainda têm dificuldade em identificar a surdez não como uma deficiência, mas sim como uma diferença. As situações diagnósticas em cada caso e o agrupamento de outras patologias são determinações relevantes, o que acarreta aos surdos a privação ao direito de serem cidadãos na sua língua, uma vez que não fazem parte do padrão criado pela sociedade.

\section{REFERÊNCIAS}

BRASIL. Ministério da Educação - MEC. Secretaria de Educação Continuada, Alfabetização, Diversidade e Inclusão. Atendimento Especial Especializado: pessoa com surdez. Brasília, DF: Câmara Nacional de Educação Básica, 2013.

DAMÁZIO, M. F. M. Atendimento educacional especializado: pessoa com surdez. São Paulo: MEC/SEESP, 2007. 52 p.

DRAGO, Rogério. Inclusão escolar e atendimento educacional especializado no contexto do projeto político pedagógico. RBPAE, v. 27, n. 3, p. 433-451, set./dez. 2011. Disponível em: <http://seer.ufrgs. br/index.php/rbpae/article/view/26413/15405>. Acesso em: 22 mar. 2016.

FERNANDES, Eulália; CORREIA, Cláudio. Bilinguismo e surdez: a evolução dos conceitos no domínio da linguagem. In: FERNANDES, Eulália (Org.). Surdez e bilinguismo. Porto Alegre, RS: Mediação, 2006. (Capítulo I).

LANE, H. A máscara da benevolência: a comunidade surda amordaçada. Lisboa: Horizontes Pedagógicos, 1992.

MAIA, Shirley Rodrigues; ARÁOZ, Susana Maria Mana de. A surdocegueira - "saindo do escuro". Revista Educação Especial, n. 17, 2001. Disponível em: <http://periodicos.ufsm.br/educacaoespecial/ article/view/5199/3189>. Acesso em: 19 mar. 2016 
MANZINI, Eduardo José; DELIBERATO, Débora. Portal de ajudas técnicas para educação Equipamento e material pedagógico especial para educação, capacitação e recreação da pessoa com deficiência física. Recursos para Comunicação Alternativa. Brasília, DF: MEC/SEESP, 2006. Disponível em: <http://portal.mec.gov.br/seesp/arquivos/pdf/ ajudas_tec.pdf>.

MARTINS, R. V. Língua de sinais e subjetividade. 2003. 170 f. Tese (Doutorado em Psicologia) - Instituto de Psicologia, Pontifícia Universidade Católica do Rio Grande do Sul, Porto Alegre, RS, 2003.

NIKITIUK, Sônia. Repensando o ensino de História. 2. ed. São Paulo: Cortez, 1999.

ORGANIZAÇÃO DAS NAÇÕES UNIDAS (ONU). Declaração de Salamanca. Salamanca, Espanha: UNESCO/Ministério da Educação e Ciência de Espanha, 1994.

PIAGET, Jean. Psicologia e pedagogia. Rio de Janeiro: Forense Universitária, 2006.

QUILES, R. E. S. Estudo de Libras. Campo Grande, MS: Editora UFMS, 2010.

RIBEIRO, Maria Clara Maciel de Araújo. O discurso acadêmico-científico produzido por surdos: entre o fazer acadêmico e o fazer militante. 2012. 263f. Tese (Doutorado em Estudos Linguísticos) - Universidade Federal de Minas Gerais, Belo Horizonte, MG, 2012. Disponível em: <http:// www.bibliotecadigital.ufmg.br/dspace/bitstream/handle/1843/ LETR-96LNYY/tese_maria_clara_maciel.pdf?sequence=1>. Acesso em: 19 mar. 2016.

RIDENTI, Marcelo. O fantasma da revolução brasileira. 2. ed. rev. e ampl. São Paulo: Unesp, 2010.

SILVA, Angélica Bronzatto de Paiva; ZANOLI, Maria de Lurdes; PEREIRA, Maria Cristina da Cunha. Surdez: relato de mães frente ao diagnóstico. Estudos de Psicologia, v.13, n. 2, p. 175-83, 2008. Disponível em: <http:// www.scielo.br/pdf/epsic/v13n2/10.pdf>. Acesso em: 20 mar. 2016. 